\title{
VENOUS PRESSURE IN GENERAL ANESTHESIA
}

\author{
By OVID O. MEYER AND WILLIAM S. MIDDLETON
}

(From the Department of Medicine, University of Wisconsin)

(Received for publication May 1, 1929)

Circulatory failure under general anesthesia has constituted a serious problem in medicine from the time of the introduction of chemical agents for this purpose. With a measure of laboratory support in the demonstration of the paralytic action of chloroform on heart muscle by Embley (1), acute dilatation of the heart came to occupy an unquestioned position of predominance in explanation of circulatory collapse under general anesthetics of whatever order. Scant clinical attention was granted the contribution of Levy (2) who demonstrated the increased irritability of the mammalian heart under light chloroform anesthesia and its reduction under deep anesthesia. Abnormal ventricular beats were observed to arise under light anesthesia and the occurrence of ventricular fibrillation as an outgrowth of this circumstance led Levy to the conclusion that this disturbance of rhythm was probably the only important circulatory cause of death under chloroform anesthesia.

Notwithstanding the sound basis of Levy's observation, cardiac dilatation remained the uncritical clinical diagnosis in the circulatory failure of general anesthesia until Levine (3) (4) directed attention to the gross disturbance of cardiac rhythm attendant upon such occurrences. Paroxysmal auricular tachycardia, auricular fibrillation and paroxysmal auricular flutter were the profound arrhythmias of auricular origin noted by him in cases presenting the features of so-called cardiac dilatation during or succeeding operation.

The situation with relation to the direct action of the several anesthetic agents on the heart muscle resolves itself into an unanimity of opinion as to the particular risk attaching to the exhibition of chloroform, since its level of toxic action on the myocardium is very 
close to the concentration required in the blood for anesthesia. Briefly stated it is 25 to 30 times as toxic to the mammalian heart as is ether (5). In the opinion of Marvin (6) the "strain" of anesthesia and operation has been grossly exaggerated and in the last analysis the heart capable of withstanding the physical demands of every-day life without symptoms will with few exceptions come through such an operative experience with no untoward effect. Sound advice is given in this rather general discussion of the subject relative to the special cardiac risks, the preparation of cardiac patients for operation and the necessity for selecting the proper anesthetist above all other considerations. Especially pertinent in the present connection is his advocacy of ethylene as the anesthetic agent of choice in cardiac invalids.

The influence of general anesthesia on the circulation and more particularly on hemodynamics has received ample notice in the literature and it is not purposed to trace this subject through its intricate ramifications. Singularly little attention has been paid to the venous side of the circulation where under the disturbed respiratory states of general anesthesia radical changes might be anticipated. A careful search of the literature has revealed only two meager references to this phase of the question. Henderson and Haggard (7) in studies of the circulation in the head-down position remarked that the venous pressure was lower after, than before, operation. In keeping with their acapnia theory of shock, death in ether excitation (8) was explained by a reduction of the carbon dioxide of the blood to one-half the normal level. Two isolated observations by Hooker (9) on the effect of general anesthesia upon the venous pressure constitute the only determinations found in the literature. A rise of the venous pressure was noted under this condition by this observer.

Recent studies (10) on the influence of respiration upon the venous pressure reaffirmed the elevation of the latter on holding the breath and on the performance of the Valsalva experiment or like physiologic acts. Contrary to the experience of Burger (11) and Kroetz (12), Meyer and Middleton (10) failed to note a primary fall in the venous pressure under the Müller experiment but recorded rises in venous pressure similar in form but less in degree than in the Valsalva experiment. Interruption of the normal respiratory rhythm without 
unusual effort effected pronounced rise of the venous pressure in the apnoeic period of Cheyne-Stokes' respiration and fall during the succeeding hyperpnoea. The latter observation coincides with the fall of venous pressure noted by Henderson, Prince and Haggard (13) and by Kroetz (12) on voluntary hyperpnoea.

Since the venous pressure reflects so distinctly, even in normal individuals, alterations in the force and the rhythm of respiration, pronounced changes in the venous pressure might be anticipated under the conditions of general anesthesia without thought of a primary circulatory responsibility for the same. The earlier division of general anesthesia into three stages has given way to the modern classification of Guedel (14) (15), in which the third stage is subdivided into four logical strata according to well defined signs. With the advent of improved methods of induction through the use of nitrous oxide preparatory to ether or ethylene administration Waters (16) divides the anesthesia into two periods, induction and maintenance. Clearly the subject in Waters' classification passes quickly through the stage of induction, which includes the older first two stages, to the maintenance or former third stage, wherein the level of anesthesia is established by the condition of the subject and the operative demands of the surgeon.

In the stage of induction the earliest effect of the anesthetic agent on the respiration may be to increase both rate and depth slightly. It has been stated that with "modern skilled anesthesia, the second stage is usually passed with little or none of the external manifestations of excitement" (15). Commonly, however, there may occur either extreme of hyperpnoea or of breath-holding. Physical effort may further complicate the picture from the standpoint of hemodynamics. On a maintenance level the respirations are quieter, more regular, and more shallow in the first stratum of the third stage whereas respiratory depression does not appear until the fourth stratum (of the third stage) of Guedel. Reflex stimulation may lead to coughing, retching, swallowing, stertor or spasmodic arrest of breathing at any stage of ether anesthesia. During maintenance these circumstances usually occur only in the lighter upper strata, but they may appear even in complete anesthesia. Respiratory paralysis is a late toxic manifestation; and since it is well beyond any therapeutic requirement of 


\begin{tabular}{|c|c|c|c|c|c|}
\hline \multirow{3}{*}{ 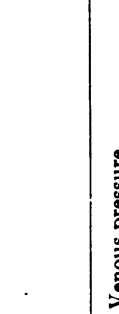 } & \multirow{2}{*}{ 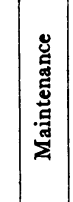 } & 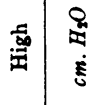 & 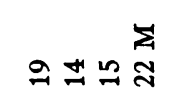 & 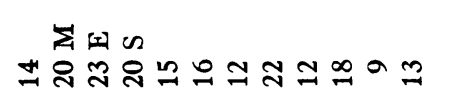 & 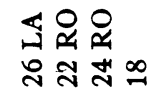 \\
\hline & & 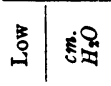 & 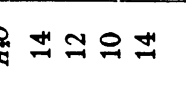 & 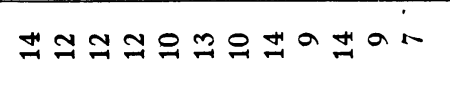 & $\stackrel{ }{\simeq} \cong \pm$ \\
\hline & 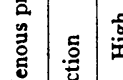 & 点 & $\stackrel{\infty}{\sim} \stackrel{\infty}{\sim}=$ & 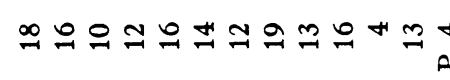 & 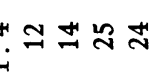 \\
\hline \multirow{7}{*}{ 密 } & 灵 & है & $a$ 의요 & 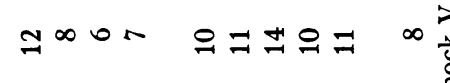 & $\underbrace{\infty}_{0} a \infty \stackrel{\infty}{=}$ \\
\hline & 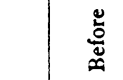 & E욤 & $+0+\infty$ & $\infty$ in $0+\infty$ or $\infty$ oa & D o in $\infty$ \\
\hline & 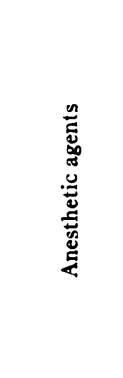 & & 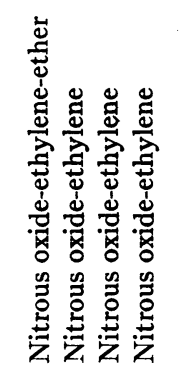 & 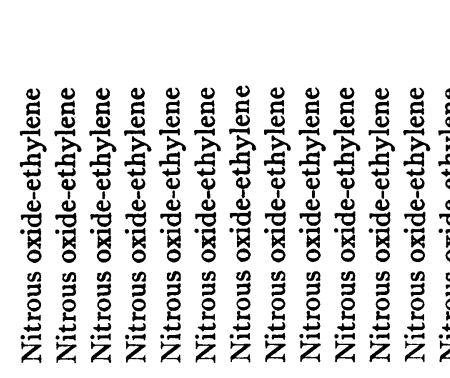 & 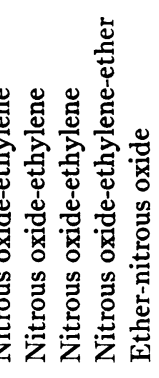 \\
\hline & 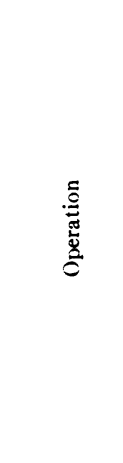 & & 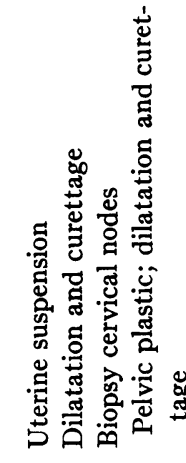 & 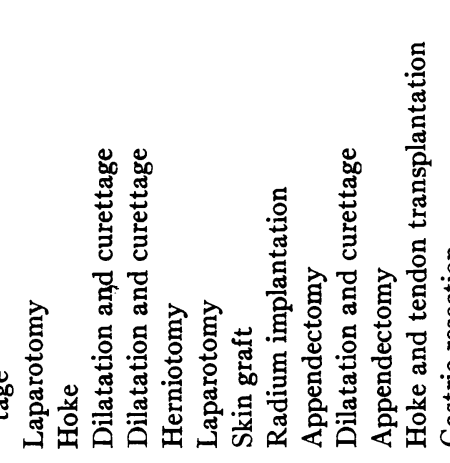 & 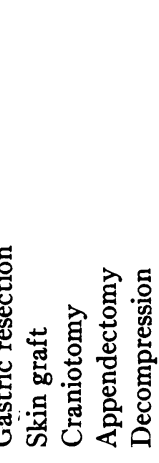 \\
\hline & . ب.ّ. & & 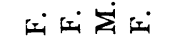 & 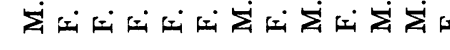 & 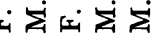 \\
\hline & $\stackrel{\$}{4}$ & & 岀a. & 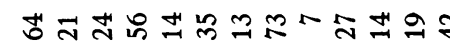 & 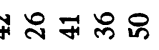 \\
\hline & 畜出 & & $\operatorname{rama}$ & 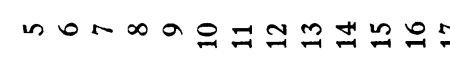 & పి శి స \\
\hline
\end{tabular}




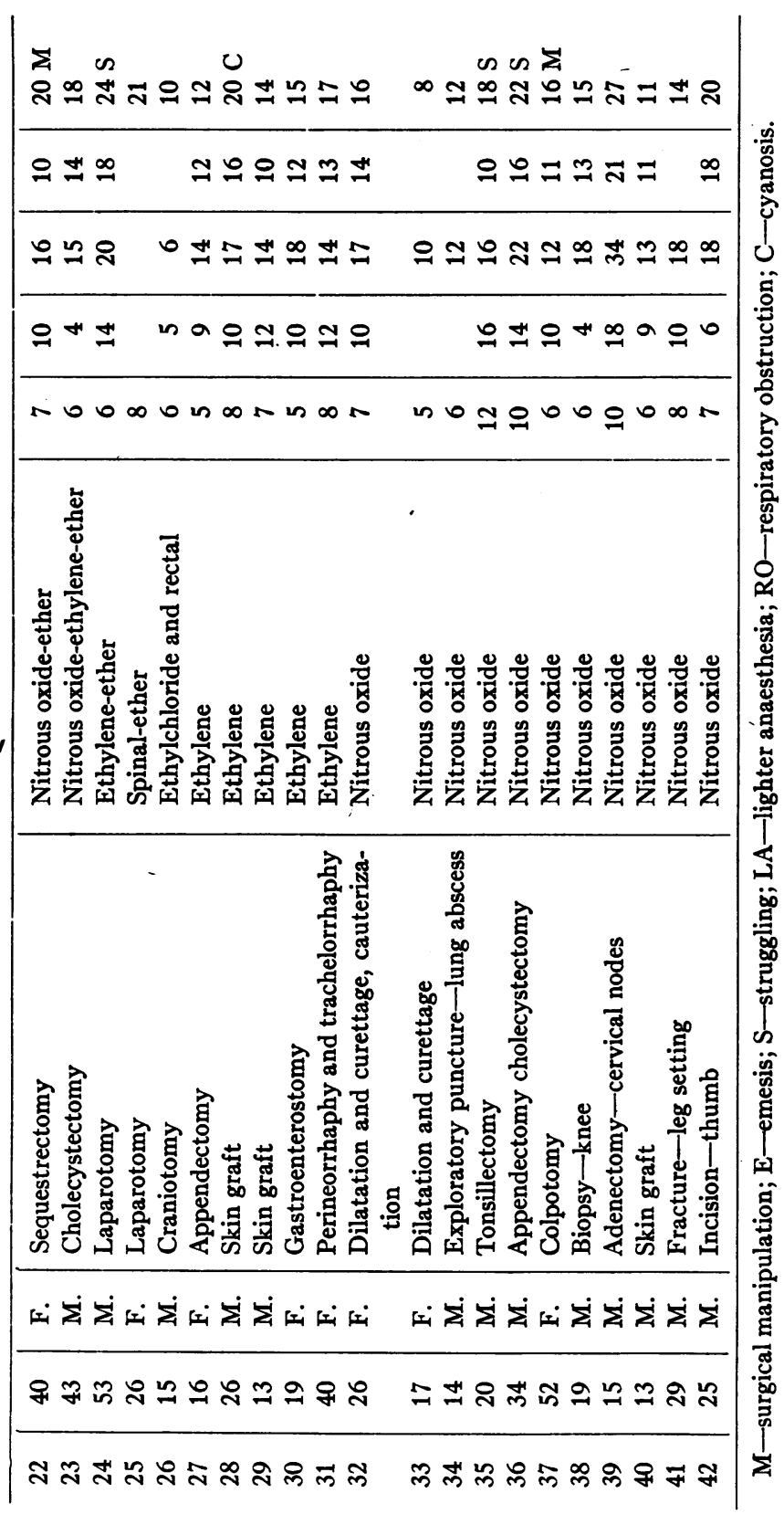


anesthesia, opportunity has not been afforded for its study in the present relation. Indeed, modern methods have limited the present observations of the venous pressure changes in the maintenance period to the upper strata of the third stage in the main.

With the thought of determining the possible effects of such alterations in normal respiratory rate, depth and rhythm upon the venous pressure, 42 subjects were studied through varying periods of general anesthesia. The Hooker-Eyster apparatus (17) for indirect venous blood pressure determination was utilized. In addition to its established accuracy this method has the great advantage of affording the opportunity for rapidly repeated observations without serious technical difficulty. All anesthetics were administered by Dr. R. M. Waters or his assistants, thus insuring a measure of uniformitysubject, of course, to the exigencies of the individual case. Early in the study the impracticability of coördinating the results on the basis of duration of the anesthesia led ultimately to the exclusion of this detail. For notes as to the stage of anesthesia Dr. Waters and his assistants are responsible. In table 1 the results have been collected. The lowest and the highest venous pressure determinations have been recorded for the periods of induction and of maintenance in each case.

The ranges of ages and of operative procedures are wide. The number of anesthetic agents utilized is small and criticism may well be directed toward this detail. However, although nitrous oxide or nitrous oxide-ethylene constitute an overwhelming majority of the group (29 of 42), representative series with ether after induction by nitrous oxide or ethylene (6) and with ethylene as the sole agent (5) have been studied. Prior to the anesthesia a single case in the entire group (case 35) exceeded the upper limit of normal venous pressure, $11 \mathrm{~cm}$. of water (18). In the induction phase physical effort and interference with the normal rhythm of respiration were routinely observed to induce prompt rises in the venous pressure. The low readings of the induction phase were in excess of the pre-anesthetic levels in all except 5 instances, where readings were available (36 cases). At this period the normal level was exceeded in 10 instances of the lowest recorded venous pressure of the 36 cases, whereas the high individual levels for the induction period exceeded the normal levels in 36 of 40 cases with adequate data. Of the 4 remaining cases 
no rule can be formulated to explain their exception. Significantly in the maintenance stage without recorded exception (36 cases) the figures for the low levels exceeded the pre-anesthetic pressures, whereas

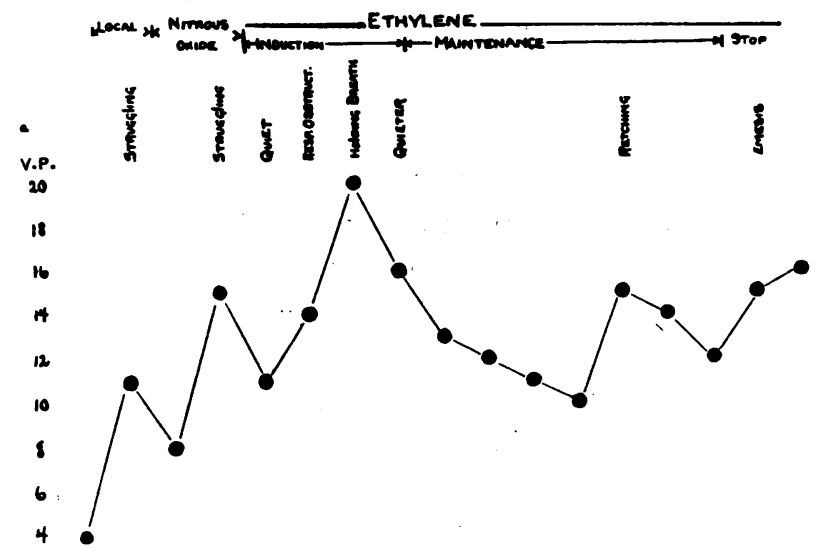

Fig. 1. A Typical Curve Showing Various Factors Afrecting Venous Pressure During Anesthesia

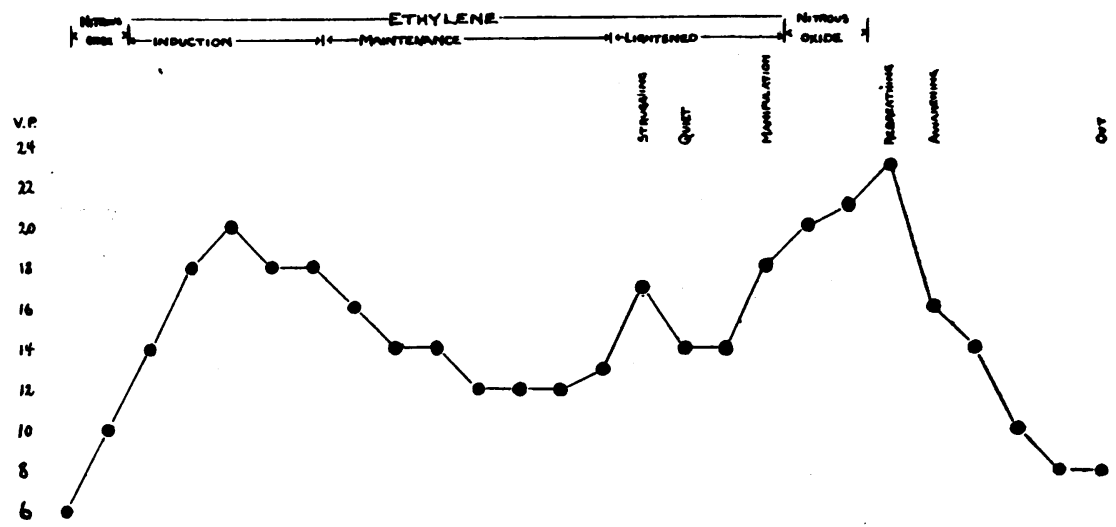

Fig. 2. A Typical Curve Showing Various Factors Affecting Venous Pressure During Anesthesia

in 9 instances the low levels for the maintenance period were below. those for the stage of induction. As to the high levels of the maintenance period 20 of 40 comparative figures showed levels lower than 
or equal to those of the induction. Explanatory legends in table 1 account for unusual rises during maintenance. A better conception of these circumstances may be gathered from characteristic curves (figs. 1. and 2).

In both curves the prompt rise during the induction of anesthesia is striking. In figure 1 the circumstances of physical exertion and respiratory interference reflect themselves immediately in venous pressure elevations. Attention is also directed to the fact that, although the level of the venous pressure tends to fall after induction, still throughout the most regular period of maintenance a plateau of venous pressure is established above the pre-anesthetic level. This phenomenon is better represented in figure 2. Release from anesthesia is marked in both curves by elevation of the venous pressure dependent upon varying conditions. In figure 2 , the venous pressure has been followed for a longer period after the withdrawal of the anesthetic agent; hence it constitutes a more characteristic curve for this period.

Two collateral observations have been made. In the first place, on several occasions carbon dioxide has been exhibited in varying proportions with an invariable rise of the venous pressure in spite of the over-ventilation of the subject. Secondly, on two occasions isolated studies of the venous pressure have been made under the circumstance of surgical shock. In each instance a low level was recorded. Unfortunately, the previous trend of the venous pressure curve was not known and these observations are too detached to have other than a suggestive importance.

\section{-CONCLUSIONS}

The significant changes in the venous pressure under the conditions of general anesthesia may be summarized as follows:

1. Coincident with the increased muscular effort and the altered respiratory function of the induction of anesthesia pronounced increases in venous pressure are noted.

2. Thereafter succeeds a plateau of somewhat elevated venous pressure throughout the maintenance of anesthesia.

3. Alterations in this plateau apparently depend upon reflex stimuli usually in a period of lightened anesthesia. 
4. Release from the anesthesia is marked by elevations in the venous pressure dependent on such acts as retching, vomiting, etc.

5. Carbon dioxide operates to increase venous pressure.

No effort is made to link these changes in the venous pressure under general anesthesia in a causal relation with the circulatory accidents of operation. The demands of ordinary life are in excess of those attending an operation under a carefully administered general anesthetic, as Marvin has stated. Nevertheless, as a measure of this particular load on the right heart, the above data are interesting.

Grateful acknowledgement is made for the hearty coöperation of Dr.

R. M. Waters and his staff in this study.

\section{BIBLIOGRAPHY}

1. Embley, E. H., Brit. Med. J., 1902, i, 817, 885 and 951. The Causation of Death during the Administration of Chloroform.

2. Levy, A. G., Heart, 1913, iv, 319. The Exciting Causes of Ventricular Fibrillation in Animals under Chloroform Anaesthesia.

3. Levine, S. A., J. Am. Med. Assoc., 1920, lxxv, 795. Acute Cardiac Upsets, occurring during or following Surgical Operations, Their Mechanism and Management.

4. Levine, S. A., Am. J. Surg. (Anesth. Supp.), 1922, xxxvi, 48. Paroxysmal Tachycardia as an Occasional Upset during Ether Administration.

5. Cushny, A. R., A Text-Book of Pharmacology and Therapeutics, Phila. 1918, Ed. 7, p. 208.

6. Marvin, H. M., N. Eng. J. Med., 1928, cxcix, 547. The Heart during Anesthesia and Operative Procedures.

7. Henderson, Y., and Haggard, H. W., J. Pharm. and Exper. Therap., 1918, xi, 189. The Circulation in Man in the Head-down Position, and a Method for Measuring the Venous Return to the Heart.

8. Henderson, Y., and Underhill, F. P., Am. J. Physiol., 1911, xxviii, 275.

I Acapnia and Glycosuria.

9. Hooker, D. R., Am. J. Physiol., 1911, xxviii, 235. The Effect of Exercise upon the Venous Blood Pressure.

10. Meyer, Ovid O., and Middleton, W. S., The Influence of Respiration on Venous Pressure. J. Clin. Invest., 1929, viii, 1.

11. Burger, Munch. Med. Wchnschr., 1921, lxviii, 1066. Ueber die klinische Bedeutung des Valsalvashen Versuches.

12. Kroetz, C., Deutsch. Arch. f. klin. Med., 1922, cxxxix, 325. Die Koeffizienten des klinische messbaren Venendruckes.

13. Henderson, Y., Prince, A. L., and Haggard, H. W., J. Pharm. and Exper. Therap., 1918, xi, 203. The Influence of Forced Breathing upon the Circulation. 
14. Guedel, A. E., Bulletin, N.A.R.S., No. 3, 1920. A Sub-classification of Third Stage Ether Anesthesia.

15. Guedel, A. E., Current Researches in Anesthesia and Analgesia, 1927, vi, 157. Stages of Anesthesia and a Re-Classification of the Signs of Anesthesia.

16. Waters, R. M., Personal communication.

17. Hooker, D. R:, and Eyster, J. A. E., Bull. Johns Hopkins Hosp., 1908, xix, 274. An Instrument for the Determination of Venous Pressure in Man.

18. Eyster, J. A. E., and Middleton, W. S., Arch. Int. Med., 1924, xxxiv, 228. Clinical Studies on Venous Pressure. 